\title{
Japanese case of follicular lymphoma of ocular adnexa diagnosed by clinicopathologic, immunohistochemical, and molecular genetic techniques
}

\author{
This article was published in the following Dove Press journal: \\ Clinical Ophthalmology \\ 30 November 2010 \\ Number of times this article has been viewed
}

\author{
Takaaki Otomo' \\ Nobuo Fuse' \\ Kenichi Ishizawa ${ }^{2}$ \\ Motohiko Seimiya' \\ Masahiko Shimura ${ }^{4}$ \\ Ryo Ichinohasama ${ }^{3}$ \\ 'Department of Ophthalmology, \\ ${ }^{2}$ Departments of Rheumatology \\ and Hematology, ${ }^{3}$ Division of \\ Hematopathology, Tohoku University \\ Graduate School of Medicine, Sendai, \\ ${ }^{4}$ Department of Ophthalmology, \\ NTT East Japan Tohoku Hospital, \\ Sendai, Myagi, Japan
}

Background: Follicular lymphomas of the ocular adnexa are very rare in Japan, with only two reported cases.

Case: A 44-year-old woman visited our clinic for treatment of ocular adnexal tumors in both eyes.

Findings: Histologic examination showed that the neoplastic lesions consisted of atypical lymphoid cells, and the tentative diagnosis was malignant lymphoma. Immunophenotypic analyses by flow cytometry and immunohistochemistry showed that the atypical lymphoid cells expressed CD45, bcl-2, CD10, CD19, CD20, IgM, and kappa light chains. The cells were negative for CD5 and other T, natural killer, or myelomonocyte antigens. Southern blot hybridization demonstrated gene rearrangement bands in the immunoglobulin JH region. Fluorescence in situ hybridization studies showed a translocation at $\mathrm{t}(14,18)(\mathrm{q} 32, \mathrm{q} 21)$. Systemic evaluations detected enlargements of both the inguinal lymph nodes and parabronchial lymph nodes.

Conclusion: Our results show that flow cytometry, molecular genetic analyses, and chromosomal examination can be useful in differentiating follicular lymphoma from marginal zone B cell lymphoma of mucosa-associated lymphoid tissue and reactive lymphoid hyperplasia.

Keywords: fluorescence in situ hybridization, follicular lymphoma, Japanese, ocular adnexa, READ system

\section{Introduction}

The classification of lymphomas has been controversial, and the Non-Hodgkin's Lymphoma Pathologic Classification Project ${ }^{1}$ has classified lymphomas by morphologic characteristics, eg, cell size, cell shape, and growth pattern. This classification was developed before immunologic or genetic techniques were available, and it created heterogenous diagnostic categories. This then resulted in relatively low reproducibility in the diagnosis among pathologists. Since the early 1980s, it has become apparent that the use of more accurate characterizations of diseases would reduce the subjectivity of morphologic diagnosis and improve the rate of correct diagnosis. Thus, increasing the information about the biology of malignant lymphomas has led to significantly better diagnosis of diseases, and newer methods, such as immunohistochemistry and molecular biology, now being used routinely in pathology laboratories.

The classification of lymphoid tumors was improved in the Revised EuropeanAmerican Lymphoma (REAL) classification, ${ }^{2}$ which was presented by the International Lymphoma Study Group in 1994. This classification was based on an update of the
Correspondence: T Otomo Department of Ophthalmology and Visual Sciences, Tohoku University Graduate School of Medicine, Sendai, Miyagi 980-8574, Japan Tel +81227177294

Fax +81227177298

Email otomo@oph.med.tohoku.ac.jp 
original Kiel classifications. ${ }^{3,4}$ This formed the basis of the new World Health Organization (WHO) classification of lymphomas in $2008,{ }^{5}$ the latest classification of lymphoma, which is based upon the foundations laid within REAL.

The majority of lymphomas occurring in the ocular adnexa are B cell non-Hodgkin's lymphomas. These are predominantly marginal zone B cell lymphomas of mucosaassociated lymphoid tissues according to the new WHO classification. According to the WHO, lymphomas that occur in the ocular adnexa are the third most common B cell lymphomas occurring in Western Europe and North America.

Follicular lymphomas of the ocular adnexa are very rare in Japan and the other Asian countries. ${ }^{6}$ They are quite difficult to diagnose by their morphology alone because their low prevalence means that most physicians have not had first-hand experience of follicular lymphoma. With the introduction of newer examination techniques, such as flow cytometry, molecular genetic analyses, and chromosomal examinations, the differential diagnosis of follicular lymphomas has become easier and more accurate.

We report a 44-year-old woman who was diagnosed with follicular lymphoma involving the ocular adnexa by flow cytometry, molecular genetic analyses, and chromosomal examinations.

\section{Case history}

A 44-year-old woman visited the Tohoku University Hospital in March 2003 complaining of painless left upper eyelid swelling. She had no relevant medical history, although her father had stomach cancer. The initial ocular examination showed that her best-corrected visual acuity was 20/20 in each eye, and her eye movements were full in both eyes. Examination of the anterior and posterior segments of both eyes was normal. Magnetic resonance imaging scans of both orbits showed a well-defined $15 \times 10 \times 10 \mathrm{~mm}$ tumor in the region of the left lacrimal gland and a $3 \times 5 \times 3 \mathrm{~mm}$ tumor in the right lacrimal gland (Figure 1). A gallium scintigram showed high uptake spots corresponding to the ocular adnexal tumors and also in both inguinal lymph nodes.

At that point, we tentatively diagnosed her with malignant lymphoma. Laboratory examinations showed serum lactate dehydrogenase of $310 \mathrm{IU} / \mathrm{L}$ (normal $=119-229$ ) and $465 \mathrm{U} / \mathrm{mL}$ of soluble interleukin-2 receptor (normal $=127-582$ ).

In April 2003, a biopsy of the left ocular adnexal tumor was performed by an anterior percutaneous approach, and the tissue was forwarded to the registration-examinationanalysis-description (READ) system, which is a comprehensive diagnostic laboratory for lymphoproliferative disorders (Koutou Biseibutsu Laboratories and Special Reference Laboratories, Tokyo, Japan). The results of their histologic examinations and other analyses of the biopsied tissues led to a diagnosis of follicular lymphoma.

The patient was referred to the Hematology Department for consultation, staging of the tumors, and further treatment. The staging investigations included full blood count, chest x-rays, computed tomography (CT) of the thorax, abdomen, head, and neck, and bone marrow biopsy. CT scans revealed enlargements of both the inguinal lymph nodes and parabronchial lymph nodes. Bone marrow biopsy was negative for lymphoma infiltration, and the patient was reported to be at Stage IIIA by the Ann Arbor clinical staging system.

The patient was treated with three cycles of chemotherapy consisting of cyclophosphamide, hydroxydaunorubicin $\left(\right.$ Adriamycin $\left.{ }^{\circledR}\right)$, vincristine $\left(\right.$ Oncovin $\left.{ }^{\circledR}\right)$, and CHOP (cyclophosphamide, doxorubicin, vincristine, and prednisone) combined with rituximab. Rituximab is a synthetic antibody that was developed using cloning and recombinant DNA technology of human and mice genes. This therapy led to a regression of the tumors and the lymphadenopathy. At the

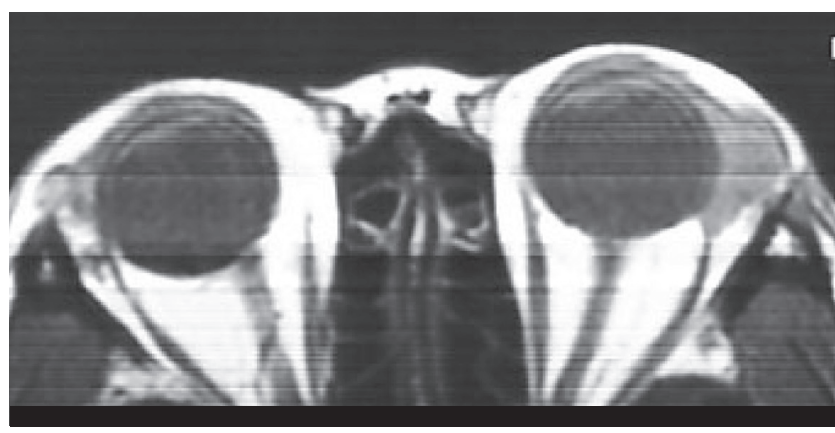

T1

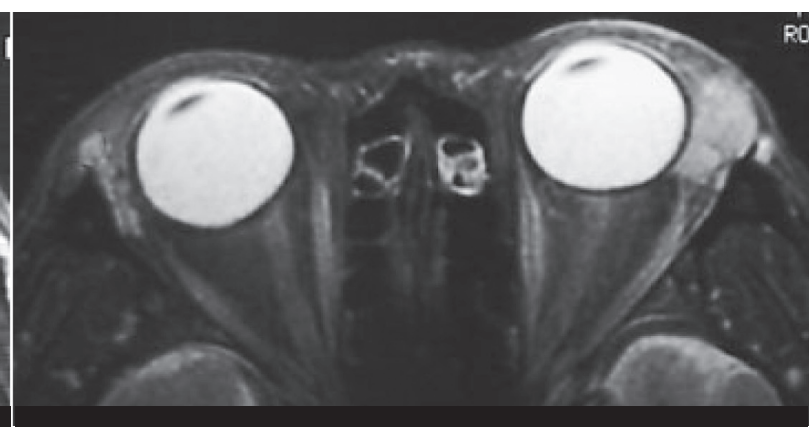

T2

Figure I Magnetic resonance imaging scans of both orbits showing a well defined $15 \times 10 \times 10 \mathrm{~mm}$ tumor in the region of the left lacrimal gland and a $3 \times 5 \times 3 \mathrm{~mm}$ tumor in the right lacrimal gland. Signals higher than that of the external muscles in TI image (right), and about the same intensity as brain cortex in the T2 image (left). 
time of the last medical examination in July 2010, the patient remained in complete remission.

\section{Materials and methods Histologic analysis}

The biopsied tissues were fixed in 20\% formalin and embedded in paraffin. Sections were stained with hematoxylin and eosin, and immunochemical staining was performed with monoclonal antibodies to bcl-2, CD3, CD10, CD20, and CD21 (Dako Japan Co, Ltd, Kyoto, Japan).

\section{Flow cytometry}

Single-cell suspensions were prepared by cutting and teasing unfixed tissues in phosphate-buffered saline. The washed cells were incubated with the different monoclonal antibodies and then injected into a Cytron Absolute flow cytometer (Ortho Diagnostic Systems, Raritan, NJ).

\section{Cytogenetic analyses}

Cells were cultured overnight in RPMI1640 with 15\% fetal calf serum without mitogenic stimulation. The G-banded metaphases of the cells were determined by trypsin-treated Giemsa stain or hybridized with chromosomal specific fluorescence probes and then karyotyped.

\section{Fluorescence in situ hybridization}

Double-labeled, two-color fluorescence in situ hybridization (FISH) was performed on cells fixed in Carnoy's fixative. The primers used were Vysis LSI IGH/BCL2 Dual Color, Dual Fusion Translocation Probe (probe for $14 q 32$ region Immunoglobulin Heavy Chain Locus and 18q21), and Vysis LSI API2/MALT1 t(11;18)(q21;q21) Dual Color, Dual Fusion Translocation Probe (probe for $11 \mathrm{q} 21$ region and 18q21 region, Abbott Laboratories, Abbott Park, IL). The chromosomal probes were labeled by nick translation. After hybridization, the probes were detected by incubation for $I g H$ gene and BCL2 gene. Nuclei were identified by 4-6-diamidino-2-phenylindole stain. The fluorescent signals were examined under a Nikon microscope (Nikon, Japan).

\section{Southern blot analyses}

High molecular weight genomic DNA was extracted from the tissues. Ten micrograms of digested DNA was electrophoresed, blotted on a nylon membrane, and then hybridized with a ${ }^{32} \mathrm{P}$-labeled probe for the $\mathrm{JH}$ gene of the immunoglobulin heavy $(\mu)$ chain. After washing, the membrane was dried and exposed to $\mathrm{x}$-ray film.

\section{Results}

Histologic examination of the biopsied tissues showed diffuse proliferation of atypical cells with occasional follicular pattern (Figure 2). The cells resembled small lymphocytes and more like marginal zone cells than centrocytes. The follicular dendritic cell meshwork was relatively dispersed rather than condensed. Immunohistochemical analysis showed that the tumor cells expressed bcl-2, CD10, CD20, and CD21. CD10 stained only a small proportion of the cells in the nodule. The presence of CD21-positive follicular dendritic cells was consistent with the follicle-like structure, and these cells were recognized as CD3-positive T cells (Figure 2).

Flow cytometry analyses showed that the atypical lymphoid cells expressed CD45, bcl-2, CD10, CD19, and CD20, IgM, and kappa, and were negative for CD5 and other T, natural killer, and myelomonocyte antigens (data not shown).

G-banded chromosome analyses were performed on 12 cells in metaphase, and a clonal cytogenetic abnormality, a 48, XX,+X,add18(q21),+add(18)[11]/46,XX[1], was identified in 11 of 12 cells (Figure 3 ). Although the abnormality included the 18q21 locus, its partner allele locus of translocation was not clear for unknown reasons. However, the fusion FISH assay showed yellow signals which consisted of the fusion of green ( $I g H$ gene) and red (BCL2 gene) signals which suggested a $\mathrm{t}(14,18)(\mathrm{q} 32, \mathrm{q} 21)$ translocation. This was detected in 49/50 cells (Figure 4). No split signal was detected with split FISH assay for the MALT1 gene and cyclin D1 gene (data not shown). Southern blot analysis showed monoclonal rearranged bands in the immunoglobulin JH region (Figure 5).

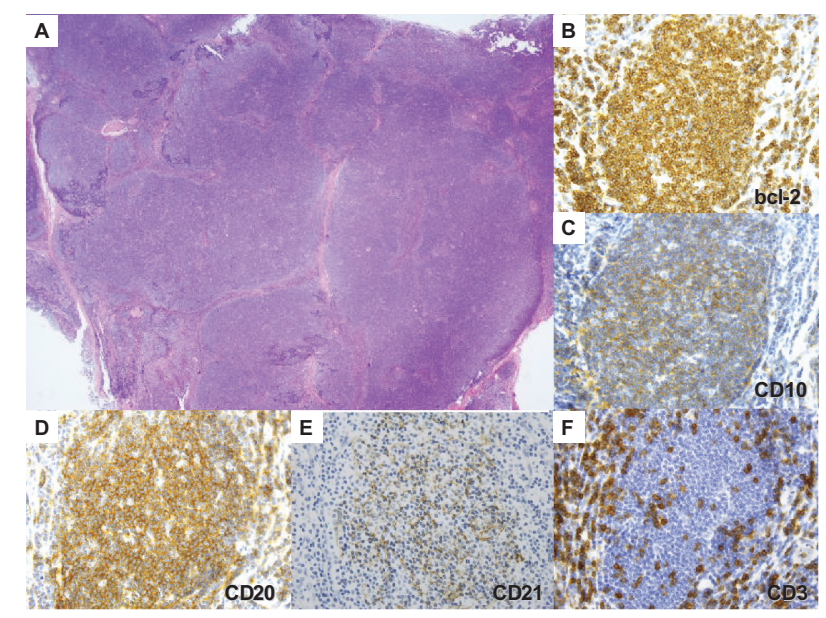

Figure 2 Histologic and immunohistochemical analyses. A) Hematoxylin and eosin image. There is a diffuse proliferation of atypical cells with occasional follicular pattern. B-F) Immunohistochemical images. The tumor cells expressed bcl-2 (B) and CDI0 stains only a small proportion of the cells in the nodule (C), CD20 (D), and CD2I (E). A follicular pattern can be seen with CD3+T cells $(\mathbf{F})$. A) magnification $\times 2$ B-F), magnification $\times 40$. 

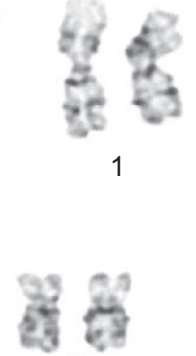

6

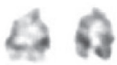

13

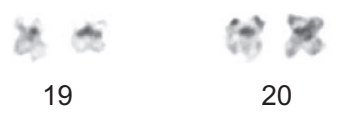

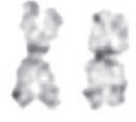

3

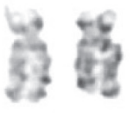

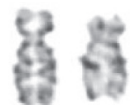

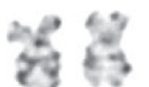

7

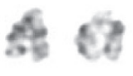

14

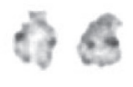

15

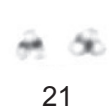

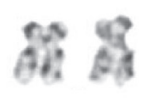

9

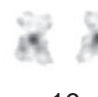

16

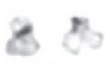

22

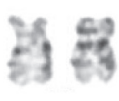

10

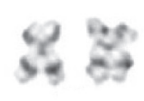

11

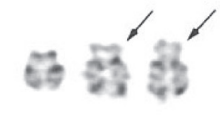

18

Figure 3 G-banded cytogenetic and spectral karyotyping. G-banded metaphase analysis revealed a 48,XX,+X,addI8(q2I),+add(I8)[II ]/46,XX[I] karyotype.

\section{Discussion}

Differentiating mantle cell lymphoma, marginal zone lymphoma, and follicular lymphoma is difficult because the differentiating characteristics are based on morphologic features, such as cell size, cell shape, and growth pattern in tissues stained with hematoxylin and eosin. Thus, mantle cell lymphoma, marginal zone lymphoma, and follicular lymphoma were placed in the same group with the same morphologic features. With the development of new techniques, such as genetic, molecular, and immunological methods, the differentiation is easier and more accurate. The 4th edition of the World Health Organization classification of tumors of hematopoietic and lymphoid tissues ${ }^{5}$ reported some new subtypes or variants of follicular lymphoma with distinct clinicopathologic and molecular genetic characteristics. Some of the early or precursor lesions of follicular lymphomas in situ are discussed.

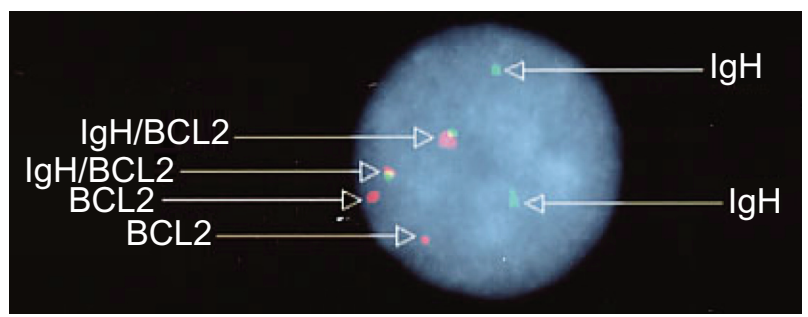

Figure 4 Analysis using fluorescence in situ hybridization demonstrated fusion yellow signals consisting of green (IgH gene) and red (BCL2 gene) signals, which directly suggested a $\mathrm{t}(14,18)(\mathrm{q} 32, \mathrm{q} 2 \mathrm{I})$ translocation, in 49/50 cells.
The differentiation of follicular lymphoma from mantle cell lymphoma, marginal zone lymphoma, and reactive lymphoid hyperplasia is important because these lymphomas exhibit different clinical behaviors and outcomes. The results of G-banded cytogenetics of our case showed chromosomal abnormality in chromosome 18q21, but no translocation partner was identified in any chromosome including the IgH/14q32 locus. However, FISH analyses using probes for BCL2 and IgH provided direct evidence for

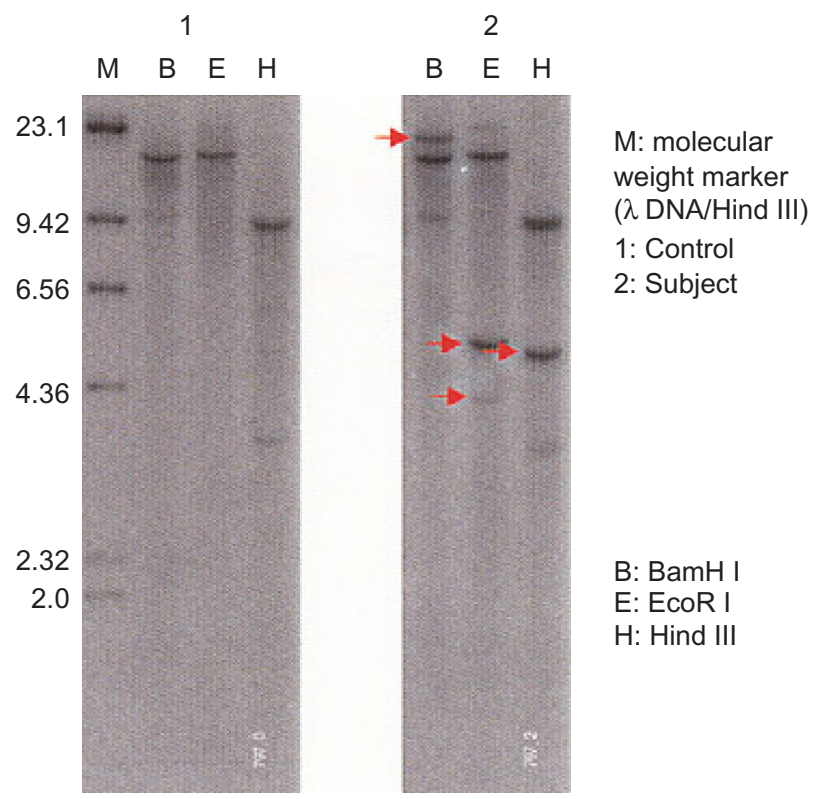

Figure 5 Southern blot analysis. Monoclonal rearranged bands were detected in the immunoglobulin $\mathrm{JH}$ region. 
their translocation. Our case was genetically characterized by a $\mathrm{t}(14,18)(\mathrm{q} 32, \mathrm{q} 21)$ translocation. This is particularly relevant because the IgH/BCL2 translocation has also been reported in extranodal mucosa-associated lymphoid tissue lymphomas in the stomach ${ }^{6-8}$ and skin. ${ }^{9}$ In addition, a MALT1 gene abnormality and $\mathrm{IgH} /$ cyclin $\mathrm{Dl}$ gene fusion was not detected in the FISH analysis. Therefore, we diagnosed the tumors as a follicular lymphoma.

In diseases such as the chronic lymphoproliferative disorders which are characterized by a very low proportion of mitotically active abnormal cells, traditional cytogenetic analysis is more likely to identify the karyotype of the normal dividing cells, and may miss the rare abnormal cell in mitosis. FISH can identify abnormalities missed by conventional cytogenetics and is helpful in the diagnosis, prognosis, and evaluation of therapy for chronic lymphoproliferative disorders such as chronic lymphocytic leukemia. ${ }^{10}$ FISH appears to be a more useful technique than other techniques and can provide the most reliable and accurate data. Immunohistochemical positivity for CD10 in the follicular lymphoma cells and their relationship with the $B C L 2$ gene in FISH could be good evidence to diagnose our case as follicular lymphoma. On the other hand, a lack of an association with the cyclinDl gene was evidence to exclude mantle cell lymphoma. In addition, no association with the MALT1 gene and the relationship with the BCL2 gene in FISH would be evidence to exclude marginal zone lymphoma. Dierlamm et al showed that the API2 gene, and a novel gene on $18 \mathrm{q} 21$, characterized by several Ig-like C2-type domains named MLT, are recurrently rearranged in $\mathrm{t}(11 ; 18)$. They suggested that the $\mathrm{t}(11 ; 18)(\mathrm{q} 21 ; \mathrm{q} 21)$ appeared to be the key genetic lesion and is found in approximately $50 \%$ of cytogenetically abnormal low-grade mucosa-associated lymphoid tissue lymphomas. ${ }^{11}$

Thus, we diagnosed our case as follicular lymphoma from a combination of the results of all of these tests.

Follicular lymphomas are found less frequently in Asian countries than in Western countries $(11 \%-33 \%),{ }^{12}$ with lower rates having been found in Japan $(6.7 \%-18 \%),{ }^{13,14}$ Korea (5.88\%), ${ }^{15}$ Hong Kong (8\%) ${ }^{16}$ Taiwan (14\%), ${ }^{17}$ and Thailand $(3.8 \%-11.1 \%) .{ }^{18,19}$ The incidence of follicular lymphoma in Japan is less than $30 \%$ of the cases in Western countries. Notably, the incidence of follicular lymphoma in mainland Europe $(11 \%-18 \%)$ is substantially less than that in North America and the UK. The reason for these differences is not known. Non-Hodgkin's lymphomas in the ocular adnexal lymphomas are rare, and they are reported to account for only about $2 \%$ of all cases of non-Hodgkin's lymphoma and about 5\%-15\% of all cases of non-Hodgkin's lymphoma at extranodal sites. ${ }^{20-22}$ In addition, follicular lymphomas are known to occur in $23 \%-31 \%{ }^{23-25}$ of ocular adnexal lymphomas. So the prevalence of follicular lymphoma in the ocular adnexa in the Japanese is very low. To the best of our knowledge, only two cases of follicular lymphoma derived from the conjunctiva have been reported. ${ }^{26,27}$ In our case, the tumor was bilateral and were localized in the lacrimal glands, and is thus not related to follicular lymphomas of the conjunctiva. However, in the analysis of the follicular lymphomas of the conjunctiva, polymerase chain reaction using the tumor DNA has detected a fusion product of the major breakpoint region of the BCL2 gene and $\mathrm{IgH} \mathrm{J}$ region. ${ }^{27}$ Because of the rareness and small sample of the ocular tumor, it was difficult to diagnose such a case as follicular lymphoma by conventional methods.

Recently, the efficacy of rituximab therapy for follicular lymphomas has been evaluated. A few clinical trials using rituximab alone for untreated follicular lymphomas ${ }^{28}$ and a few cases of conjunctival follicular lymphomas treated with rituximab alone have been reported. ${ }^{27}$ Generally, the common side effects of rituximab are not severe, and no side effect of rituximab was observed in our case.

In summary, our case with tumors in both eyelids was diagnosed as follicular lymphoma with a combination of the findings of immunohistochemical and molecular genetic techniques. We conclude that the insights into the pathogenesis of lymphoid malignancies through new techniques such as genetic, molecular, and immunologic methods would help as complementary methods for the diagnosis, and lead to more accurate diagnosis and proper treatment.

\section{Acknowledgment}

The authors thank Dr Duco I Hamasaki for editing the manuscript.

\section{Disclosure}

The authors report no conflicts of interest in this work.

\section{References}

1. National Cancer Institute sponsored study of classification of nonHodgkin's lymphomas: Summary and description of a Working Formulation for clinical usage. The Non-Hodgkin's Lymphoma Pathologic Classification Project. Cancer. 1982;49:2112-2135.

2. Harris NL, Jaffe ES, Stain H, et al. A revised European-American classification of lymphoid neoplasms: A proposal from the International Lymphoma Study Group. Blood. 1994;84:1361-1392.

3. Gerard-Marchant R, Hamlin I, Lennert K, et al. Classification of nonHodgkin's lymphoma. Lancet. 1974;2:406-408.

4. Stansfeld A, Diebold J, Noel H, et al. Updated Kiel classification for lymphomas. Lancet. 1988;1:292-293. 
5. Swerdlow SH, Campo E, Harris NL, et al, editors. WHO Classification of Tumours of Haematopoietic and Lymphoid Tissues. 4th ed. Lyon: IARC Press; 2008.

6. Libra M, Gloghini A, Malaponte G, et al. Association of $\mathrm{t}(14 ; 18)$ translocation with $\mathrm{HCV}$ infection in gastrointestinal MALT lymphomas. J Hepatol. 2008;49:170-174.

7. Libra M, de Re V, Gloghini A, et al. Frequency of bcl-2/IgH translocation in patients with non-Hodgkin's lymphoma and chronic hepatitis $\mathrm{C}$ virus infection. Minerva Gastroenterol Dietol. 2005;51:165-170.

8. Nakamura S, Ye H, Bacon CM, et al. Gastric MALT lymphoma with $\mathrm{t}(14 ; 18)(\mathrm{q} 32 ; \mathrm{q} 21)$ involving IGH and BCL2 genes that responded to Helicobacter pylori eradication. J Clin Pathol. 2007;60:1171-1173.

9. Palmedo G, Hantschke M, Rütten A, et al. Primary cutaneous marginal zone B-cell lymphoma may exhibit both the $\mathrm{t}(14 ; 18)(\mathrm{q} 32 ; \mathrm{q} 21) \mathrm{IGH} /$ BCL2 and the $\mathrm{t}(14 ; 18)(\mathrm{q} 32 ; \mathrm{q} 21)$ IGH/MALT1 translocation: An indicator for clonal transformation towards higher-grade B-cell lymphoma? Am J Dermatopathol. 2007;29:231-236.

10. Glassman AB, Hayes KJ. The value of fluorescence in situ hybridization in the diagnosis and prognosis of chronic lymphocytic leukemia. Cancer Genet Cytogenet. 2005;158:88-91.

11. Dierlamm J, Baens M, Wlodarska I, et al. The apoptosis inhibitor gene API2 and a novel 18q gene, MLT, are recurrently rearranged in the $\mathrm{t}(11 ; 18)(\mathrm{q} 21 ; \mathrm{q} 21)$ associated with mucosa-associated lymphoid tissue lymphomas. Blood. 1999;93:3601-3609.

12. Anderson JR, Armitage JO, Weisenburger DD, et al. Epidemiology of the non-Hodgkin's lymphomas: Distributions of the major subtypes differ by geographic locations. Non-Hodgkin's Lymphoma Classification Project. Ann Oncol. 1998;9:717-720.

13. Lymphoma Study Group of Japanese Pathologists. The World Health Organization classification of malignant lymphomas in Japan: Incidence of recently recognized entities. Pathol Int. 2000;50:696-702.

14. Aoki R, Karube K, Sugita Y, et al. Distribution of malignant lymphoma in Japan: Analysis of 2260 cases, 2001-2006. Pathol Int. 2008;58: 174-182.

15. Ko YH, Kim CW, Park CS, et al. REAL classification of malignant lymphomas in the Republic of Korea: Incidence of recently recognized entities and changes in clinicopathologic features. Hematolymphoreticular Study Group of the Korean Society of Pathologists. Revised European-American lymphoma. Cancer. 1998;83:806-812.
16. Ho FC, Todd D, Loke SL, et al. Clinico-pathological features of malignant lymphomas in 294 Hong Kong Chinese patients, retrospective study covering an eight-year period. Int J Cancer. 1984;34: 143-148.

17. Chen CY, Yao M, Tang JL, et al. Chromosomal abnormalities of 200 Chinese patients with non-Hodgkin's lymphoma in Taiwan: With special reference to T-cell lymphoma. Ann Oncol. 2004;15:1091-1096.

18. Intragumtornchai $\mathrm{T}$, Wannakrairoj $\mathrm{P}$, Chaimongkol $\mathrm{B}$, et al. NonHodgkin's lymphomas in Thailand. A retrospective pathologic and clinical analysis of 1391 cases. Cancer. 1996;78:1813-1819.

19. Sukpanichnant S, Sonakul D, Piankijagum A, et al. Malignant lymphoma in Thailand: Changes in the frequency of malignant lymphoma determined from a histopathologic and immunophenotypic analysis of 425 cases at Siriraj Hospital. Cancer. 1998;83:1197-1204.

20. Decaudin D, de Cremoux P, Vincent-Salomon A, et al. Ocular adnexal lymphoma: A review of clinicopathologic features and treatment options. Blood. 2006;108:1451-1460

21. Fisher SG, Fisher RI. The epidemiology of non-Hodgkin's lymphoma. Oncogene. 2004;23:6524-6534.

22. Knowles DM, Jakobiec FA, McNally L, Burke JS. Lymphoid hyperplasia and malignant lymphoma occurring in the ocular adnexa (orbit, conjunctiva, and eyelids): A prospective multiparametric analysis of 108 cases during 1977 to 1987. Hum Pathol. 1990;21:959-973.

23. Fung CY, Tarbell NJ, Lucarelli MJ, et al. Ocular adnexal lymphoma: Clinical behavior of distinct World Health Organization classification subtypes. Int J Radiat Oncol Biol Phys. 2003;57:1382-1391.

24. Jakobiec FA. Ocular adnexal lymphoid tumors: Progress in need of clarification. Am J Ophthalmol. 2008;145:941-950.

25. Ferry JA, Fung CY, Zukerberg L, et al. Lymphoma of the ocular adnexa: A study of 353 cases. Am J Surg Pathol. 2007;31:170-184.

26. Azumi A, Hirai K, Tamura Y, et al. A case of follicular lymphoma derived from the conjunctiva. Nippon Ganka Gakkai Zasshi. 2002;106: 420-425.

27. Takahira M, Okumura $\mathrm{H}$, Minato $\mathrm{H}$, et al. Primary conjunctival follicular lymphoma treated with the anti-CD20 antibody rituximab and low-dose involved-field radiotherapy. Jpn J Ophthalmol. 2007;51:149-151.

28. Cohen Y, Solal-Celigny P, Polliack A. Rituximab therapy for follicular lymphoma: A comprehensive review of its efficacy as primary treatment, treatment for relapsed disease, re-treatment and maintenance. Haematologica. 2003;88:811-823.
Clinical Ophthalmology

\section{Publish your work in this journal}

Clinical Ophthalmology is an international, peer-reviewed journal covering all subspecialties within ophthalmology. Key topics include: Optometry; Visual science; Pharmacology and drug therapy in eye diseases; Basic Sciences; Primary and Secondary eye care; Patient Safety and Quality of Care Improvements. This journal is indexed on Submit your manuscript here: http://www.dovepress.com/clinical-ophthalmology-journal

\section{Dovepress}

PubMed Central and CAS, and is the official journal of The Society of Clinical Ophthalmology (SCO). The manuscript management system is completely online and includes a very quick and fair peer-review system, which is all easy to use. Visit http://www.dovepress.com/ testimonials.php to read real quotes from published authors. 